\title{
Conceptul 'Treime' din Paradisul lui Dante reflectat în traducerile românești
}

\author{
Cristian Ungureanu* \\ Facultatea de Litere, Universitatea „Alexandru Ioan Cuza”, Bd. Carol I 11, 700506 Iaşi, România
}

\section{Despre articol}

Istoric:

Primit 17 aprilie 2015

Acceptat 13 mai 2015

Publicat 17 iulie 2015

Cuvinte-cheie:

Treime

Paradisul

Dante

traducere

desemnare

\begin{abstract}
Rezumat
Traducătorul Paradisului lui Dante întîmpină o dificultate de dublu nivel. Mai întîi, pe cea rezultată din limitarea inerentă condiției umane în a exprima inefabilul, pe care o resimte autorul; apoi, pe cea rezultată din dificultatea limbajului pe care Dante însuși îl construiește pentru a depăși prima dificultate. Reușita sau eșecul unei traduceri se măsoară în funcție de procentul din mesajul original pe care traducătorul îl face accesibil cititorului de altă limbă, iar acest procent poate fi constatat numai prin analiza comparativă. Lucrarea de față își are ca fundament analiza comparativă dintre textul original al Paradisului și traducerile sale românești, cu referire la contextele în care apare conceptul 'Treimii'; acest examen arată că în versiunile românești sînt și echivalări reușite, fidele semantic și formal, dar și cazuri de „trădare” a originalului.
\end{abstract}

\section{Introducere}

Un traducător trebuie să țină cont nu doar de regulile strict lingvistice, ci și de elementele culturale care apar inevitabil într-un text. Este necesar să legăm conceptul de traducere de varietatea modurilor de a gîndi și de a vorbi care, de-a lungul istoriei, s-a concretizat în limbi, culturi, literaturi și societăți diferite. O traducere nu reflectă doar evenimente și lucruri dintr-o anumită epocă într-o cultură diferită, ci poate să contribuie la difuzarea și răspîndirea unor noi modele și stiluri care se stabilesc în structurile lingvistice și culturale din mediul în care pătrunde, și pot să influențeze transformarea chiar evoluția unei alte culturi. Există un raport destul de strîns între tradiția literară a unei culturi și traducerile existente în cadrul acesteia. Actul de traducere merge dincolo de un simplu proces mecanic sau de un simplu transfer interlingvistic, el comportă o comparație nu numai între două sisteme lingvistice diferite, ci și între două culturi. Astfel, înțelegerea unui text reprezintă obiectivul pricipal al traducerii, însă atingerea acestuia trece de la datele unei culturi din care se traduce spre integrarea lor în contextul cultural în care ajung, fără ca cei care se vor apropia de text să aibă sentimentul că le este impusă o cultură care le este în totalitate străină.

Pelerinul Dante este conștient, încă de la începutul ultimei cantice a Divinei Comedii, de condiția sa de homo viator, care se angajează într-o călătorie nemaiauzită ce nu ține cont de legile naturii. Pentru a exprima această condiție neobișnuită, el folosește verbul trasumanar, un neologism dantesc care desemnează depăşirea condiției umane, marcînd singularitatea acțiunii întreprinse. Însă lucrul acesta nu este suficient; poetul trebuie să coboare printre muritori pentru a le împărtăși experiența, chiar dacă îi lipsește instrumentul expresiv, așa cum el însuși afirmă: „e vidi cose che ridire / né sa né può chi di là sú discende" (Par., I, v. 5-6). Deși imposibilitatea limbajului uman de a exprima divinitatea î pune multe limite poetului, acesta nu ezită să definească, să numească şi să se prevaleze de o serie de concepte pentru a exprima lumea divină.

Mai departe, traducătorul trebuie să facă faţă acestei duble provocări: mai întîi, să perceapă lumea pentru care Dante însuși a inventat modalități de expresie; apoi, să găsească vehiculele potrivite pentru a

*Adresă de corespondență: cristiungureanu@libero.it. 
transmite cititorului lumea lui Dante, cu dubla ei realizare, ca sens și ca formă (sau, mai exact, ca formă pusă în slujba sensului).

În cele ce urmează, ne vom opri asupra conceptului de 'Treime', analizînd lexicalizarea lui în original și apoi alegerile traducătorilor în transpunerea lor în limba română. Ne vom rezuma la traducerile lui George Coşbuc şi a Etei Boeriu, considerate cele mai importante transpuneri integrale ale Divinei Comedii ${ }^{1}$.

\section{Desemnarea Treimii în textul lui Dante și în traduceri}

În primul rînd, e de remarcat faptul că, în textul Divinei Comedii, Dante nu folosește niciodată sintagma "Sfînta Treime” ca atare (Santissima Trinità). Se pot identifica două modalități principale de desemnare a acesteia: una legată de aspectul numeral al Treimii, prin recursul la cifra trei, și desemnarea prin enumerarea metaforică, prin menționarea în acelaşi context a celor trei persoane ale Trinității. Întrucît numărul ocurențelor este destul de mic, vom analiza toate contextele în care apare conceptul, în ordinea apariției în textul-sursă.

\subsection{Aspectul numeral al Treimii}

Modalitatea cea mai uzuală de desemnare a conceptului în discuție în textul Paradisului este referirea la aspectul său numeral, prin enunțarea cifrei trei, urmată sau nu de un determinat substantival (care numește direct sau metaforic constituenții acestei persoane colective).

Sfînta Treime, tema dominantă a cîntului al XIII-lea, este desemnată prin enunțarea cifrei constitutive (tre) urmată de substantivul care desemnează, la modul direct și general, constituenții: trepersone in divina natura (Par., XIII, v. 27). De fapt, contextul conține o descriere a misterului trinitar, urmată imediat de precizarea dublei naturi a Fiului: ma tre persone in divina natura, / e in una persona essa e l'umana. G. Coșbuc urmărește întocmai structura versului din original. Traducătorul înlocuiește adjectivul divin (divina natura) cu veşnic (trei persoane în veşnica natură), echivalare care, chiar dacă nu redă exact sensul din originalul italian, nu influențează receptarea ideii de Treime; însă la nivelul contextului, care se referă la misterul întrupării, nu este clară, în traducere, ideea că o singură persoană a divinitații se face om: $c i$ trei persoane-n veșnică natură / unind divinu-n trupul firii-umane (la Dante, această distincție este foarte clară: din cele trei persoane ale Treimii, una doar este purtătoarea și a naturii umane: e in una persona essa e l'umana). Eta Boeriu face abstracție de explicațiile din textul dantesc și echivalează conceptul prin numele divin al Trinității, luat ca atare: ci Treimii i se cîntă / și sfintei taine-a întrupării-osana.

În Par., XIV, v. 28-29, prin referirea la Treime (simbol al unităţii circulare), Dante exprimă, ajutînduse de muzicalitatea poeziei, un mister inexprimabil în termeni raționali, cel al unităţii și în același timp al diferențierii persoanelor divine: Quell'uno e due e tre che sempre vive / e regna sempre in tre én due én

\footnotetext{
${ }^{1}$ Menționăm aici cele mai importante traduceri românești în versuri ale Divinei Comedii: Dante Alighieri, Divina Comedie. Infernul, traducere de G. Coșbuc, ediție îngrijită și comentată de Ramiro Ortiz, Editura Cartea Românească, București, f. a. [1924], cf. și G. Coșbuc, Opere, VII. Traduceri, Dante, Divina Comedie, 1. Infernul, ediție critică de Gh. Chivu, prefață și comentarii de Alexandru Duțu, Editura Minerva, București, 1985; Dante Alighieri, Divina Comedie. Purgatoriul, traducere de G. Coșbuc, ediție îngrijită și comentată de Ramiro Ortiz, Editura Cartea Românească, București, f. a. [1927]; Dante Alighieri, Divina Comedie. Paradisul, traducere de G. Coşbuc, ediție îngrijită şi comentată de Ramiro Ortiz, Editura Cartea Românească, București, f. a. [1932]; cf. și George Coșbuc, Opere. III. Traduceri. Divina Comedie, Comentariu la Divina Comedie, Introducere, ediție, note, comentarii, glosar și repere critice de Gh. Chivu, Academia Română, Fundația Națională pentru Literatură și Artă, București, 2013; Dante Alighieri, Divina Comedie, în românește de Eta Boeriu, note și comentarii de Alexandru Duțu și Titus Pîrvulescu, Editura pentru Literatură Universală, București, 1965 (cu numeroase reeditări); Dante, Infernul, interpretare românească, note și un cuvînt înainte de George Buznea, Editura Univers, București, 1975; Dante, Purgatoriul, interpretare românească și note de George Buznea, Editura Univers, București, 1978; Dante Alighieri, Divina Comedie, în românește de Giuseppe Cifarelli, ediție îngrijită de Titus Pîrvulescu și prefaţată de Alexandru Ciorănescu, Editura Europa, Craiova, 1993, cu ilustrații de Marcel Chirnoagă (reeditată în 1998, Editura Dacia, Cluj-Napoca); Dante Alighieri, Divina Comedie. Infernul, text bilingv, cu versiune românească, note, comentarii, postfață și repere bibliografice de Răzvan Codrescu, Editura Christiana, București, 2006; Dante Alighieri, Divina Comedie. Infernul, traducere din italiană și comentarii de Marian Papahagi, cu o prefață de Irina Papahagi, ediție îngrijită, introducere și completarea comentariilor de Mira Mocan, Editura Humanitas, București, 2012.
} 
uno. G. Coșbuc păstrează superbul chiasm al dublei enumerări din original (unu-doi-trei - trei-doi-unu), reuşind să transmită și muzicalitatea circulară a versurilor care se referă la un mister pe care cuvintele nu au cum să-l descifreze: Căci Unu, Doi și Trei ce-n veci unit/și-n Trei şi-n Doi şi-n Unule deodată. Ideea de circularitate se pierde în traducerea Etei Boeriu, care decide să abordeze rezumativ ceea ce Dante a vrut să transmită prin jocul algebric al poeziei sale: Cel pururi viu în trei fäpturi pe-o treaptă /și care-n trei e domn nețărmurit.

Desemnarea prin numeral a Treimii se face și prin alăturarea, paradoxală, a celor două numerale, trei (expresie a componenței) și unu (expresie a unității): trino e uno (Par., XV, v. 47). Apare aici, din nou, conceptul de Dumnezeu unic și întreit în același timp: „Benedetto sia tu, (...), trino e uno / che nel mio seme se’ tanto cortese"; cel care exprimă acest imn de laudă este Cacciaguida ${ }^{2}$, care își manifestă recunoștința față de un Dumnezeu mărinimos (cortese) cu familia sa (mio seme). În ambele variante de traducere analizate, simpla enumerare adjectivală din originalul dantesc este echivalată prin formula de incluziune trei în unul. În rest, G. Coșbuc echivalează formula de început a imnului de laudă printr-un calc de expresie, deși corespondentul uzual al termenului benedetto din limba română este binecuvîntat: „Binevorbit să fii tu, trei în unul, / c-aşa de bun te-arăţi seminței mele”, iar Eta Boeriu echivalează formula de binecuvîntare prin alt incipit imnografic și adjectivul cortese $e^{3}$ prin blînd, care este un atribut al divinitații, fără îndoială, dar nu pe acesta îl actualizează Dante în contextul de față: „Mărire ție, ce ești trei într-unul, / că blînd te-arăţi cu seminția mea".

Într-o altă terțină (Par., XXIV, v. 139-141), Dante vorbește despre dogma Trinității ${ }^{4}$, proprie credinței creștine: în Dumnezeu sînt trei persoane, care sînt în același timp una și trei, astfel încît, spune autorul Divinei Comedii, despre acestea se poate vorbi folosind verbul a fi atît la persoana a III-a plural (sînt), cît și la persoana a III-a singular (este): E credo in tre persone etterne, e queste / credo una essenza si una e si trina, I che soffera congiunto "sono" ed "este".

G. Coșbuc reușește să echivaleze cu fidelitate terțina originală, atît la nivelul sensului, cît și la cel al expresiei: și-n trei persoane-eterne cred, și-aceste / atari sînt Un și-n trei atari se-mbină/ că sufere să-i zici și sînt și este. Eta Boeriu introduce termenul făpturi, nepotrivit cu esența divinității fiindcă are sensul '(ființe) create': Şi cred în trei fäpturice-n Paradis/ sînt una-n fapt și întreite-atare, / că se-mpreună-n „sînt” și-n „este” (...).

În desemnarea Treimii nu este implicat doar numeralul cardinal, ci și cel multiplicativ, cu valoare adjectivală: Ob trina luce chén unica stella / scintillando a lor vista, si li appaga! / guarda qua giuso a la nostra porcella (Par., XXXI, v. 28). Expresia se referă la Treime; Dante invocă divinitatea să-şi întoarcă privirea către pămînt pentru a vedea dezordinea și violența neamului omenesc ${ }^{5}$. G. Coșbuc echivalează direct expresia care desemnează Treimea și invocaţia din original, păstrînd atît metafora luminii, cît și determinarea sa numerală: Lumină triplă, ce desfeți din una / de-a pururi stea, pe-atîția fericiți, / privește-n jos să vezi la noi furtuna. Eta Boeriu înlocuiește metafora luminii stelare cu metafora focului, păstrînd desemnarea prin numeralul cu valoare adjectivală: $O$, faclă întreită care-alini / c-un singur foc alai defericiți! / Privește jos ce vijelii ne-ațin. În echivalarea adjectivului trino care desemnează Trinitatea, G. Coşbuc optează pentru neologismul triplu, în timp ce Eta Boeriu recurge la consacratul întreit (obţinut printr-o schimbare a categoriei gramaticale însoțită de prefixare).

Sfînta Treime este desemnată, în textul lui Dante, și prin metafora sferelor, însoțită, firește, de nu-

${ }^{2}$ Cacciaguida este un strămoș al lui Dante din secolul al XII-lea, singurul, de altfel, se pare, despre care poetul însuși avea cunoștință.

${ }^{3}$ Cortése: 'di corte, gentile, garbato'; (la Dante) 'generoso, prodigo', cf. DELI.

${ }^{4}$ „Così definito dal concilio Lateranense IV del 1215: «unus solus est verus Deus, æternus et immensus... Pater et Filius et Spiritus Sanctus, tres quidem personæ sed una essentia, substantia seu natura »”, Anna Maria Chiavacci Leonardi, în Dante Alighieri, La Divina commedia. Paradiso, p. 675, nota la versurile 139-141.

${ }^{5}$ Aşa cum se întîmplă şi în alte locuri din Paradis, poetul face apel la glasul lui Boethius, care îi este alături în împărăția cerurilor, aşa cum Vergilius îi fusese alături în Infern şi în Purgatoriu. Acesta spunea, în Mîngîierile filosofiei: „Priveşte acum pămîntul plin de jale / Oricine ai fi cel ce dirigui toate / Noi, bună parte a lucrării tale, / Plutim pe marea vieții la întîmplare” (Boethius, Mîngîierile filosofiei, I, V, v. 42-45). 
meralul cardinal. Cele trei sfere se referă la Sfînta Treime și reprezintă definiția clasică a acestui concept teologic: trei persoane egale, dar în același timp distincte: Ne la profonda echiara sussistenza / de l'alto lume parvemi tre giri / di tre colori e d'una contenenza (Par., XXXIII, v. 116-117). Din profunda și luminoasa existență a lui Dumnezeu (profonda e chiara sussistenza) apar trei cercuri de trei culori, care au același conținut. Imaginea dantescă face referire la Treime, definită de teologie ca unitatea celor trei persoane divine distincte: Tatăl, Fiul (Isus Cristos) și Duhul Sfînt. Adjectivul chiaro, provenit din lat. clārus, $-a$, -um ('1. Loud, sonorous; 2. Bright, shining; 3 Seeing clearly, clear', OLD, s.v.), are sensul 'puro, limpido, terso, trasparente'; sau, cu valoare substantivală, pe acela de 'luce, luminosità' (DELI, s.v.); în contextul acesta, este folosit cu sensul 'luminos'. Pentru a exprima sensul 'esență, substanță eternă, Dante creează substantivul sussistenza ${ }^{6}$.

Traducerea lui G. Coşbuc rămîne, într-o bună măsură, fidelă textului dantesc: şi-n clara ei şi-adînca-i subzistență / văzui trei cercuri în lumina vie, / de trei colori și-aceeași continență.

Traducătorul alege echivalenți românești care au același etimon cu cei din original: clar 'care dă o lumină neîntunecată de nimic, fără umbre, luminos cu multă lumină; subzistență, folosit aici cu sensul învechit 'existență, prezență' (cf. DLR). În schimb, substantivul continență este rezultatul unui calc semantic după originalul italian: rom. continență provine din fr. continence și are sensul 'reținere, oprire (de la plăceri) înfrînare, cumpătare' (DLR, s.v.); aici, traducătorul împrumută sensul termenului italian echivalent, 'conținut'. Riscul acestui procedeu este, însă, ca cititorul să nu înțeleagă semnificația versurilor.

În cealaltă traducere analizată, imaginea prin care Dante vrea să descrie Treimea este neclară, mai ales pentru că nu apare ideea de unitate: În însăşsi profunzimea ei văzui / trei brîuri felurite la culoare, / la fel de largi în roți și pricepui.

Utilizarea, de către Eta Boeriu, a substantivului brîu ('1. cingătoare lată, purtată de țărani și țărance; 2. Ornament vopsit; 3. P. ext. Partea corpului pe care o încinge brîul, mijlocul', cf. DA) pentru exprimarea ideii de cerc este nesatisfăcătoare întrucît, prin caracterul ei plastic și prin sensul înrădăcinat în română (sensul 1. din DA), poate crea o cu totul altă imagine decît cea din originalul italian (și anume, în loc de perfecțiunea cercului, cititorul ar putea rămîne cu imaginea unor brîuri țărănești, greu de pus în relație cu atributele divinității a căror imagine se presupune că o reprezintă). De asemenea, alegerea nefericită a acestui substantiv privează textul de sensurile implicite pe care le presupune metafora sferei (este simbol al divinității în reprezentările artei creștine, al lumii de dincolo, al unității și perfecțiunii în tradiția greacă etc.) (Chevalier \& Gheerbrant, 1993, p. 223).

\subsection{Desemnarea prin enumerarea metaforică a persoanelor Treimii}

Acest procedeu este folosit de două ori în Paradis. Primul context este cel din Par., XIII, v. 55-57: ché quella viva luce che si mea / dal suo lucente, che non si disuna / da lui né da l'amor ch'a lor s'intrea. Terțina reprodusă definește Sfînta Treime și încearcă să prezinte metaforic această realitate ultramundană unică și întreită în acelaşi timp, afirmînd că Fiul (viva luce) vine de la Tatăl (il suo lucente), adică are aceeași substanță și este nedespărțit de acesta și de Sfîntul Duh (l’amor).

Ambii traducători modifică desemnarea referenților din alegoria dantescă. G. Coșbuc echivalează expresia care se referă la Dumnezeu Tatăl, în original prezentat ca lumină, printr-o alta care se referă la primatul și întîietatea acestei persoane divine în fața celorlalte două: De Primul cel ce-o naște-apoi, aceea / lumina vie-n veci nu se desparte / și nici de-amor ce-i fața lor a treia. Eta Boeriu are o abordare explicativă a metaforelor dantești; ea echivalează viva luce prin mai explicitul apelativ al Fiului lui Dumnezeu, verbul sfînt, lumina, iar amore prin expresia directă din limba română a referentului, sfintul dub: Căci verbulsfint, lumina ce pornește / din foc divin, de el nu se desparte / și nici de sfintul dub ce-i întreiește.

În alt context din Paradisul (XIII, v. 79-81), Treimea este prezentată prin alăturarea altor trei metafore care desemnează cele trei persoane și care colaborează în vederea realizării perfecțiunii creației: caldo

\footnotetext{
${ }^{6}$ După DELI, substantivul respectiv este atestat pentru prima dată la Dante: sussistenza, s. f.: 'il sussistere; ciò che sussiste' (av. 1321, Dante), din lat. subsistō, -ere ('to stand firm', cf. OLD).

${ }^{7}$ În Crezul niceano-constantinopolitan se spune despre Fiul lui Dumnezeu că este „lumină din lumină”.
} 
amor (Duhul Sfînt), la chiara vista (Isus Cristos), prima virtù (Dumnezeu Tatăl): Però se 'l caldo amor la chiara vista / de la prima virtù dispone e segna, / tutta la perfezion quivi s’acquista. Dată find dificultatea interpretativă a versurilor, nu toți comentatorii sînt de acord că aici ar fi vorba despre toate cele trei ipostaze ale divinității; ni s-a părut, însă, edificatoare interpretarea dată de Anna Maria Chiavacci Leonardi ${ }^{8}$, de care am ținut cont în analiza acestui pasaj. Perfecțiunea se produce atunci cînd Dumnezeu creează prin intermediul Duhului Sfint, care este iubire, care dispune (segna) imprimarea ideii arhetipale produsă de Fiul, imaginat ca ochiul (vista) prin care vede și acționează Tatăl. În versiunea lui G. Coșbuc, pasajul sună astfel: Deci cînd Virtutea prim-astfel dispune / și-mprim-aşa iubirea sa-nfocată, / s-atinge-atunci suprema perfecțiune. Am reprodus integral versiunea lui G. Coșbuc a terținei în cauză pentru a arăta că ea omite echivalarea sintagmei ce poate fi interpretată drept metaforă pentru cea de-a doua persoană divină (Fiul), pe care nu o numește nici direct; așadar, crearea imaginea Treimii, în versiunea lui G. Coșbuc, eșuează.

Eta Boeriu optează pentru menționarea lipsită de echivoc a celor trei persoane ale Trinității: Iubirea însă, cînd pecetea vie / a Tatălui în verbul sfint o-mplintă, / desăvîrșit e ce-a fost scris să fie.

\section{Concluzii}

În crearea imaginii Treimii, concept de maximă importanță în economia textului, Dante se folosește de două modalități. Prima, și cea mai frecventă, este desemnarea prin numeralul cardinal trei, însoțit sau nu de un determinat substantival (care exprimă direct—persona — sau indirect—prin metafore: sfere, lumină— constituenții Treimii) sau de alte numerale (doi, unu). A doua modalitate de desemnare a Treimii se face prin enumerarea constituenților săi, la nivel metaforic.

Pentru traducătorii români, echivalarea prin numeral pare cea mai abordabilă, în sensul că este cel mai ușor de echivalat. În schimb, metaforele sînt adesea „trădate” în procesul traducerii, ceea ce se petrece în două direcții: sau înlocuirea cu altă metaforă (sugestiv este cazul brîului din traducerea Etei Boeriu a terținei din cîntul XXXIII, v. 116-117), sau descifrarea metaforei prin numirea directă a persoanelor divine (ceea ce face, cu precădere, tot Eta Boeriu).

Poezia înseamnă nu doar ceea ce se spune, ci-mai ales—ceea ce se sugerează; ea conține, aşadar, o anumită doză de inefabil care face ca receptarea mesajului său să depindă (și) de subiectivitatea cititorului. $\mathrm{Cu}$ atît mai mult, mesajul unei poezii receptate prin intermediul unei traduceri riscă să fie distorsionat din cauza dublei interpretări pe care o primește aceasta: interpretarea dată de traducător, în timpul procesului de deconstrucție/reconstrucție a sensului, și interpretarea de către cititor, în funcție de fundamentele sale culturale, de sensibilitatea sa. Faptul că în capodopera lui Dante nu este nimic întîmplător, că toate au un loc bine circumscris în globalitatea viziunii dantești, face ca demersul la care se angajează un traducător să fie mult mai complex decît o simplă echivalare a termenilor, fie ea echivalare fidelă sau adaptare, iar pentru o traducere reuşită este nevoie, dincolo de har și echilibru filologic, de o muncă de cercetare asiduă.

\section{Bibliografie}

Boethius și Salvianus, Scrieri. Articole teologice și mîngîierile filosofiei. Despre guvernarea lui Dumnezeu, traducere de David Popescu, cuvînt înainte de Nicolae Corneanu, Editura Institutului Biblic și de Misiune al Bisericii Ortodoxe Române, București, 1992.

Chevalier, J. \& Gheerbrant, A. (1993). Dicționar de simboluri, vol. 3, P-Z, Editura Artemis, București.

Dante, Divina Commedia. Inferno. Purgatorio. Paradiso, con il commento di Anna Maria Chiavacci Leonardi, Arnoldo Mondadori editore, Milano, 1994.

Dante, Divina Commedia, commento a cura di Giovanni Fallani e Silvio Zennaro, Newton Compton editori, Roma, 2005.

Dante Alighieri, Commedia. Paradiso, a cura di Emilio Pasquini e Antonio Qualio, Garzanti editore, Milano, 1999.

\footnotetext{
${ }^{8}$ „Nella terzina fortemente sintetica si adombra ancora una volta l'idea della creazione come atto trinitario: se lo Spirito Santo ('l caldo amor, soggetto) dispone e imprime con azione diretta la viva luce del Figlio (la chiara vista, oggetto) che procede dal Padre (la prima virtù), quivi, cioè nella creatura così formata, si otterrà il massimo della perfezione”, Anna Maria Chiavacci Leonardi, în Dante Alighieri, La Divina commedia. Paradiso, p. 373, nota la versurile 79-81.
} 
Dante, Divina Comedie. Paradisul, în românește de George Coșbuc, comentariu de Alexandru Balaci, Editura de stat pentru literatură și artă, București, 1957.

Dante, Divina Comedie, în românește de Eta Boeriu, note și comentarii de Alexandru Duțu și Titus Pîrvulescu, Editura pentru Literatură Universală, București, 1965.

DA = Dicționarul limbii române, tomul I, partea A-B, București, 1913; tomul I, partea a II-a, C, București, 1940; tomul I, partea a III-a, D-De, București, 1949; tomul II, partea I, F-I, București, 1934; tomul II, partea a II-a, J-Lacustru, București, 1937, Ladă-Lepăda, București, 1940, Lepăda-Lojniță, București, 1940.

DLR = Dicționarul limbii române, serie nouă, Academia Română, București, 1965 și urm.

DELI = Dizionario etimologico della lingua italiana, Manlio Cortelazzo, Paolo Zoli, Zanichelli Editore, Bologna, 1980.

Enc. D. = G. A. Scartazzini, Enciclopedia dantesca. Dizionario critico e raggionato di quanto concerne la vita e le opere di Dante Alighieri, vol. I, $A-L$, Milano, 1896, vol. II (parte prima), $M-R$, Milano, 1898, vol. II (parte seconda), $S-Z$, Milano, 1899. OLD = Oxford Latin Dictionary, Oxford University Press, 1968. 